\title{
Influences of Environmental Conditions during Infancy on Final Body Stature
}

\author{
NICOLAUS DAHLMANN ${ }^{(31)}$ AND KURT PETERSEN \\ 1. Medizinische Klinik, Universitäts-Krankenhaus, Hamburg-Eppendorf, Germany
}

\begin{abstract}
Summary
In the following article we shall investigate the Second World War with its consequences on nutrition and other living conditions for the German population to try to determine whether lack of nutrition plus other deficiencies, which infants were subjected to in Germany during this time, had any influence on their adult stature.

The following data formed the basis of our investigation: (I) nutrition of infants and school-aged children during the years 1939-1948; (2) stature and weight of 6-year-old boys between 1907 and 1948; (3) infant mortality between 1935 and 1950; (4) stature of 19-year-old men who were born between 1938 and 1951.

From Figure 5 it can be seen that the mean stature of 19-yearold men born between 1938 and 1951 (except for those born in 1944 and 1945) rose steadily (secular acceleration). The plot of the yearly rate of acceleration (Fig. 6 ) reveals a minimum in 1944-1945, and follows a general downward, U-shaped trend $(P$ $<0.05)$. On the other hand, infant mortality between 1941 and 1949 follows an upward $U$-shaped trend $(P<0.05)$.

For the 6- to 8-month-old infants during 1945-1948 nutrition was far worse than that during the preceding years. It is even likely that the nutrition for the infants had already begun to decrease in quality in 1942.

We find, therefore, a close correlation between the years of high infant mortality and the growth deficiencies of the men born during these years. Since we must assume that the nutritional situation for babies and infants worsened steadily after 1942 until it is apparent that a number of environmental factors directly influence human growth.

The conclusion of our analysis is that a deficit of growth occurring after the end of the fourth year can be compensated fully. We conclude, furthermore, that the growth deficits which arise before the fourth year, on the other hand, cannot be compensated fully even if good or excellent environmental conditions follow.
\end{abstract}

\section{Speculation}

Growth is genetically programmed and subjected to a feedback mechanism, which can be influenced by a number of envirommental factors. It will be the task of future investigations to determine which parameters bring their influence to bear and how they relate to each other. In this connection hormone and genetic researchers can combine their experiences and try to modify the general model.

It has long been known that there is a correlation between environment and growth in general, and between nutrition and growth in particular $(3,6,14,28,29)$. In this context, investigations on the effects of malnutrition on the development of an organism $(3,7,12,24)$ have been of special interest. It was found that growth deficiencies are dependent to a great extent on the severity and duration of nutritional insufficiencies $(4,5$, $7,12,24,28)$. The growth deficiencies, however, can be compensated in part (catch-up growth) $(4,5,12,23)$. How much catch-up growth is possible remains to be determined (23). World War II, with its consequences on nutrition and other living conditions for the German population, might be seen as an experiment the data of which perhaps can provide an answer to this question. In the following we shall investigate this data to try to determine whether lack of nutrition and other deficiencies which babies and infants were subjected to in Germany during the World War II had any influence on their adult stature.

\section{MATERIALS}

The following data formed the basis of our investigation: (l) nutrition of infants and school-aged children during the years 1939-1948; (2) stature and weight of 6-year-old boys between 1907 and 1948; (3) infant mortality between 1935 and 1950; (4) stature of 19-year-old men who were born between 1938 and 1951 .

\section{NUTRITIONAL SITUATION DURING WAR AND POSTWAR PERIODS}

Only a few papers exist that discuss conditions of nutrition during the war and postwar period and concurrently differentiate according to age groups and the constitution of nutrition. In this respect, the paper of Droese (8) for the region of SchleswigHolstein and that of Adam (1) for the township of Erlangen are very important. As the results were worked out for different regions and show similar trends for comparable periods (Adam has analyzed the period of October 14, 1946 through July 20, 1947 as well as June 1, 1948 through January 3,1949 ), we shall restrict ourselves to reproducing the results of Droese as representative for the general situation. As a guide for his work Droese used the nutritional standards laid down by the American Food and Nutrition Board in 1945 for different age groups. Figure 1 indicates that the nutrition of $6-8$-month-old infants in war and postwar periods was satisfactory both in quantity and in quality. When one compares the individual years, however, it can be pointed out that nutrition for the 6- to 8-month-old infants during 1945-1948 was far worse than that during the preceding years. During the second half of 1945 , in particular, a decrease in quantity and quality of foods such as milk, butter, and sugar occurred, reflecting a deficit in those foods which are of primary importance for bottle-fed children. Only after the currency reform of June 1948 did the nutrition of babies and infants develop parallel to that of the whole population. The decisive improvement in the nutritional situation thus took place after 1949, as can be seen from the Ernährungsbericht of 1969 (9). Nutrition of the older children had long been of a lower quality (Fig. 2). Finally, from 1945-1948, a constant quantitative and qualitative deficiency in nutrition existed for children 10 years of age and older. On April 6, 1942, the ration scales were substantially reduced and the situation of nutrition for adults 

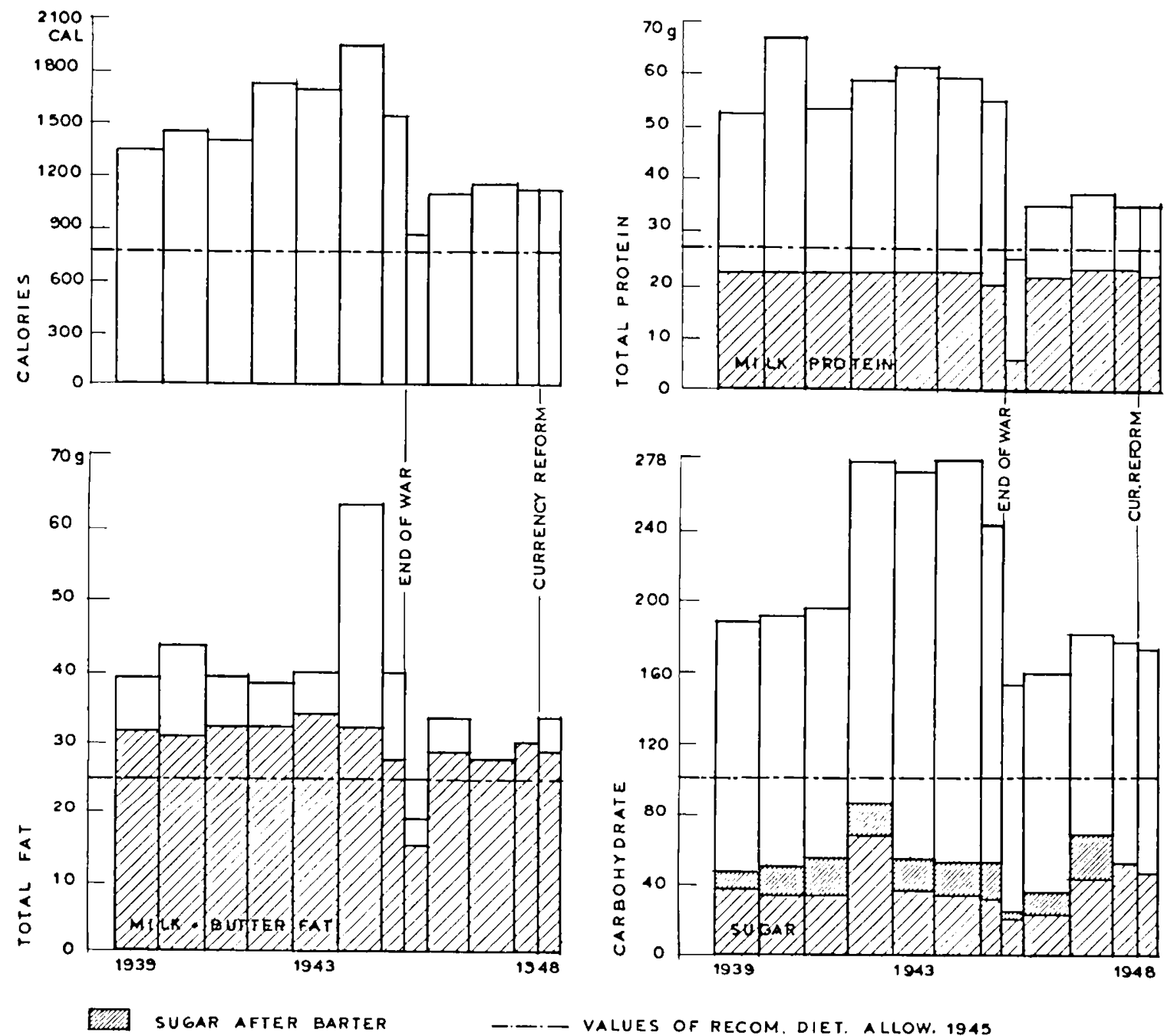

Fig. 1. Analysis of the nutritional situation of 6-8-month-old babies in Germany during the years 1939-1948. (Reprinted from Droese and Rominger (8) with permission.)

worsened until it reached a low in 1945 (16). Since a family must be considered as a unit with regard to food consumption, we cannot exclude the possibility that parts of infant nutrition were shared by the entire family. Therefore, it is likely that the nutrition for the infants began to decrease in quality as carly as 1942.

\section{STATURE OF INFANTS AND JUVENILES}

The paper of Freund (10) provides a survey of the trends in stature of 1-6-year-old infants since 1907. Figure 3 shows that there are no noteworthy differences in body height of 1-6-yearold boys born between 1945 and 1948 compared to those born between 1934 and 1940. No secular acederation took place in this period. This finding has been supported graphically in different papers $(8,21)$. Several authors even reported a deficit in height of children 10 years of age and older for 1945-1948 compared with the standards $(1,8,21,26)$.

\section{INFANT MORTALITY}

The mortality of infants can be taken as a reflection of the living conditions of infants $(8,10,13,19)$. Here, several factors have to be considered, such as insufficient nutrition, insufficient sanitation, increased susceptibility to infection as a result of high population density and poor housing, insufficient health and body care, cold weather, and mental stress $(8,13)$. We utilized the data of infant mortality in Hamburg (11). This data is probably representative of Germany, since there is similar data for other regions, e'g., Bavaria (17).

Infant mortality begins to rise in 1942, reaching a peak in 1945 (Fig. 4). Using a procedure developed by Ofenheimer (22), we tested whether or not the timespan between 1938 and 1951 with its maximum in 1945 shows a significant change in trend. This procedure is a modification of Kendall's rank correlation coefficient $\tau(18)$, based upon a principle of Siegel and Tukey (25) to test the biton trend. The result was that (taking a one-sided test because only the upward U-form trend is of interest) the infant mortality between 1941 and 1949 follows an upward U-form trend $(P<0 .(15)$.

\section{STATURE OF 19-YEAR-OLD MEN}

The material presented below is taken from the physical examinations of 19-year-old men from the army of West Germany. The height was measured in accordance with a regulation whereby the body height was noted in full centimeters. Readings below $0.5 \mathrm{~cm}$ are rounded downwards, readings of $0.5 \mathrm{~cm}$ and more are rounded upwards. Men were dressed only in shorts (15). The number of men examined per year of birth ranges from $300,000-450,000$. From Figure 5 it can be seen that the mean stature of 19-year-old men born between 1938 and 1951 except for those born in 1944 and 1945 -rose steadily (secular acceleration). The difference between the values of two neighboring birth years gives a measure for the yearly rate of acceleration. The plot of the yearly rate of acceleration (Fig. 6) reveals a 

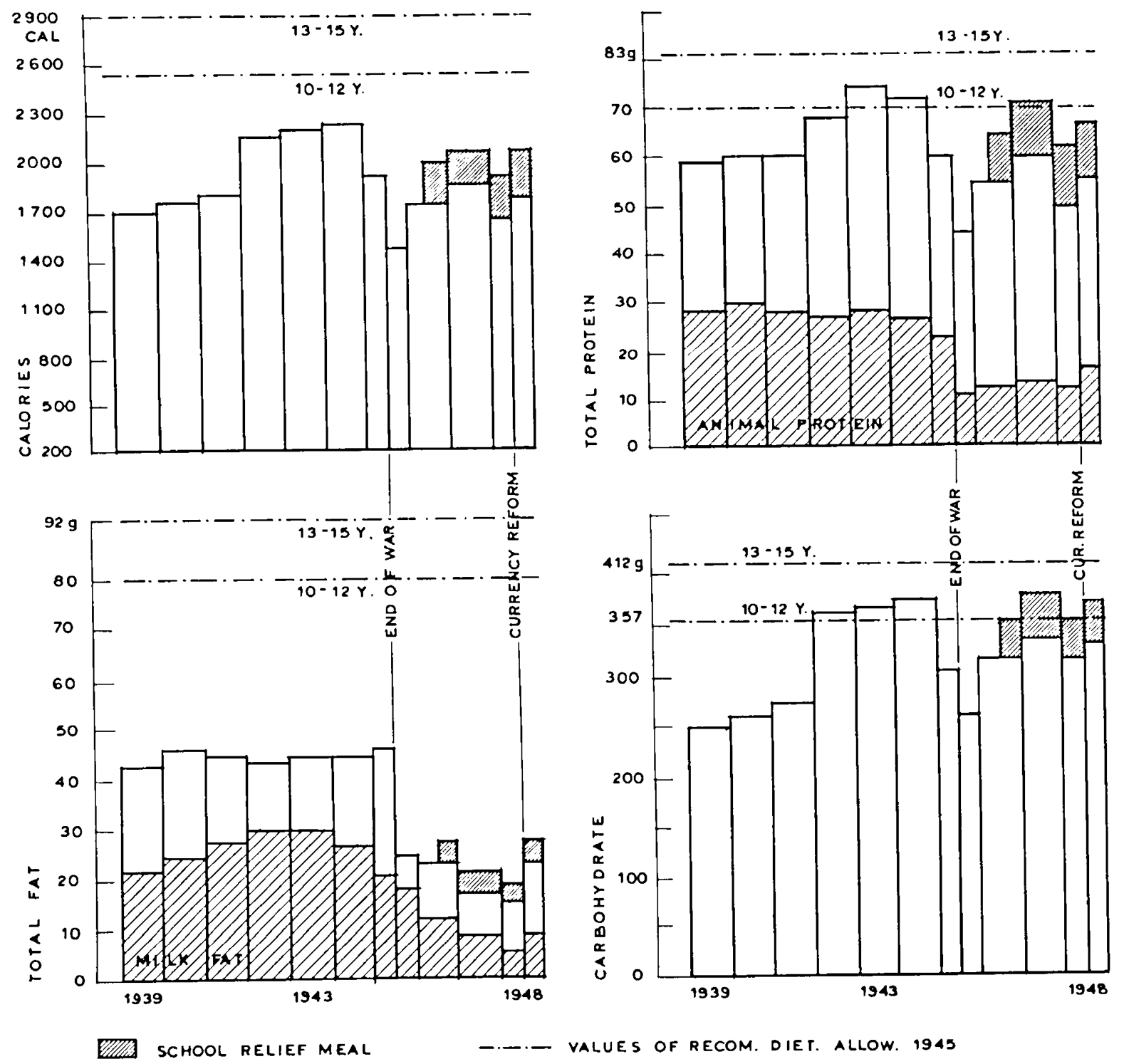

Fig. 2. Analysis of the nutritional situation of 10-12 and 13-15-year-old children in Germany during the years 1939-1948. (Reprinted from Droese and Rominger (8) with permission.)

minimum in 1944-1945, and follows a general downward, Ushaped trend. This trend was also proven to be significant at the $5 \%$ level with the procedure of Ofenheimer (22).

Furthermore, we pursued the question of whether the height of 19-year-old men determined from the different years of birth could actually be taken as the final body size. The possibility that a person can compensate deficiencies in growth during childhood through a prolonged period later in life could not be ruled out initially (3). For the last 20 or 30 years in the United States and Germany $(2,20,27)$, it has been determined that the adult height for men is reached at the age of 18 or 19 . Since maximum annual increase in height, puberty, and end of growth are directly correlated $(20)$, it is possible to interpolate the end of growth from a plot of the annual growth rates. Thus, the data of school-aged children of Hamburg (11) (which can be regarded as a representative sample of the more comprehensive Bundeswehr data) can be used to show that the men of the questionable birth years 1942-1949 had indeed fully completed growth at the age of 19.

\section{DISCUSSION}

Analysis of body stature, indicates that the secular acceleration is interrupted beginning in 1942 . It decreases steadily until
1944, and in 1945 it even sinks below zero (i.e., to the level of 1943) (Fig. 5). After 1946 it increases continually again, but does not fully normalize until 1948-1949. We find a close correlation between the years of high infant mortality and the growth deficiencies of the men born during these years. Since we must assume that the nutritional situation for babies and infants worsened steadily since 1942 , it is apparent that a number of environmental factors (all caused by common material insufficiencies since 1942) directly influenced human growth. The secular acceleration shows a change in trend since 1942. Children who were born in 1941 experienced the harshest conditions as 4-year olds in 1945. The body stature of these 4-year olds corresponds to that of 4-year olds born in 1935. Still, the stature of the 19-year-old men born in 1941 lies within the secular trend. The stature of 19-year-old men who were born after 1942 , on the other hand, shows no secular increase. We conclude, therefore, that a deficit of growth occurring after the end of the fourth year can be compensated fully. This compensation, called catch-up growth, is possible even if the deficits of growth lic far below the standard statistics. This conjecture is founded on the fact that the points on the graph of the children born in 1938 to 1941 lie in the secular trend, although these children suffered from poor conditions for at least 3-4 years and had to live under continuous conditions of quantitative and qualitative 
nutritional insufficiency as 10-year olds in 1948. We conclude, furthermore, that the growth deficits which arise prior to the fourth year cannot be compensated fully even if good or excellent envirommental conditions follow. This is supported by the observation that men born in 1945 show no secular acceleration

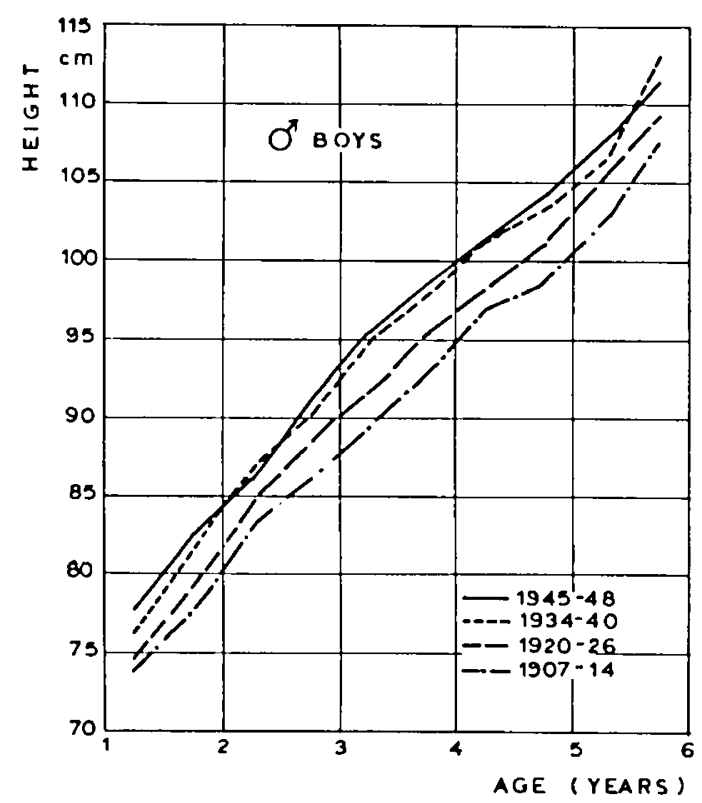

Fig. 3. The development of stature of 1-6-year-old boys during four different periods between 1907 and 1948. The distances between curves reflect the secular acceleration that took place between the respective periods. (Reprinted from Freund (10) with permission.) of growth, although living conditions improved greatly after 1949, when the boys were 4 years old.

In short, the conclusion of our analysis is that environmental conditions during the first 4 years of life can strongly influence the final body stature. A consequence of poor conditions during this critical period thus is that the organism cannot develop to its full potential of growth. The effects last until adulthood and cannot be compensated completely by normal conditions at a later time. As a working hypothesis for the determination of final boly stature, we propose that a number of parameters interact to affect the genetically determined program of growth. With increasing realization of the potential for growth, more subtle parameters bring their influence to bear. Further investigations are required to verify this model.

\section{CONCLUSION}

We investigated the question of whether environmental conditions in infancy can be correlated to the final stature of adults. The environmental conditions in Germany during the World War II provided a natural experiment to answer this question. First, we have tried to outline the living conditions of infants during this period. Next, we analyzed, graphically and statistically, the secular acceleration trends of the body stature of the men that were born or grew up during this period. Attempting to correlate environment during infancy and final body stature, we arrived at the following conclusions. The living conditions of the first 4 years of life are of great importance for the development of an individual's stature. Conditions experienced during the first 4 years of life have effects until adulthood and cannot be compensated fully by normal conditions at a later stage. We can observe a catch-up growth to equalize all lack of growth if the responsible environmental insufficiencies are experienced after the fourth year.

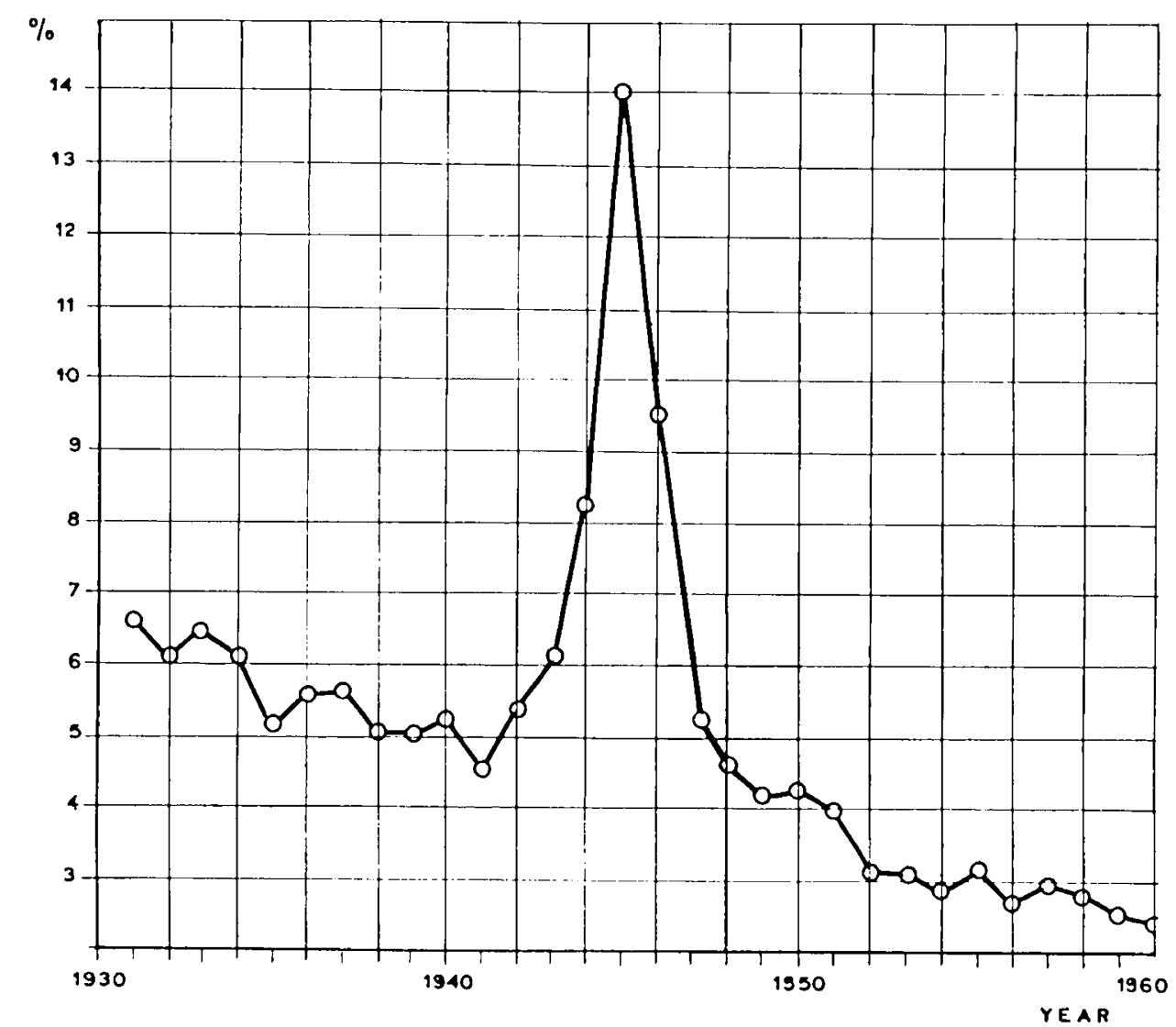

Fig. 4. The infant mortality in Hamburg during 1931-1960 plotted as a percentage of children who died within the first year of life. 


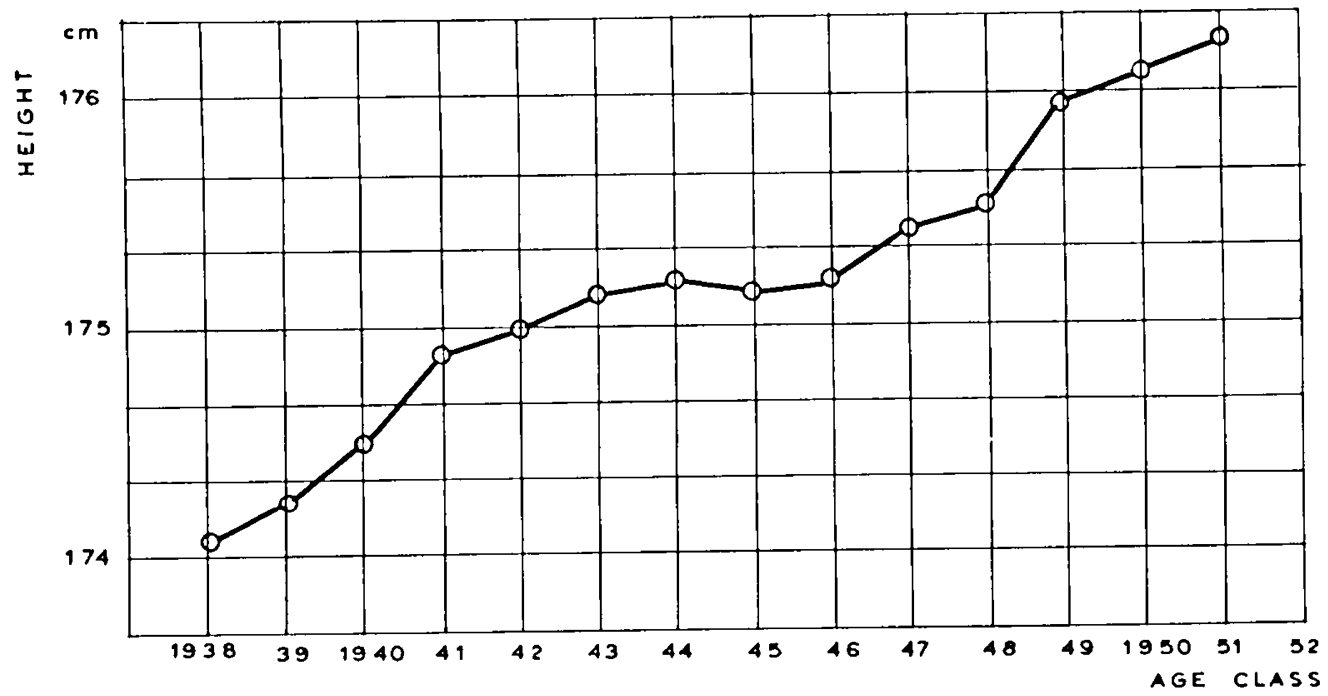

Fig. 5. Mean stature of 19-year-old men at the time of their physical examinations for the military. The years presented are years of birth.

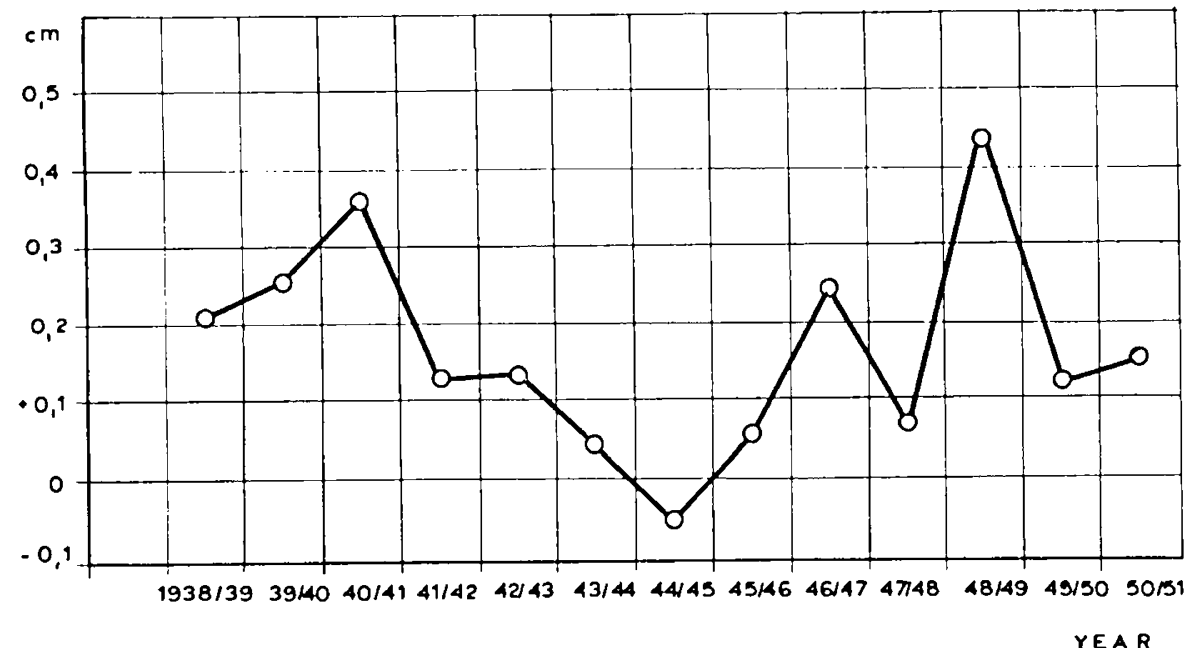

Fig. 6. Yearly rates of acceleration of growth. Differences in the adult body stature (19-year-old men) between subsequent years. (Values for height are taken directly from Figure 5.)

\section{REFERENCES AND NOTES}

1. Adam, A.: Proposal of a rational distribution of all different milk proteins of nutrition in order to eliminate a protein deficiency in the nutrition of today's youth. Milchwissenschaft, 4: 65 (19.49).

2. Bayley, N.: Growth curves of height and weight by age for boys and girls, scaled according to physical maturity. J. Pediat., 48: 187 (1956).

3. McCance, $R$. A and Widdowson, E. M. The effect of nutrition on growth, form and final stature. Klin. Ernahrungs. II. Wiss. Veroffentl. Deut. Ges. Ern., 15: 74 (1966).

4. Chase. P. and Martin, H. P.: Undernutrition and child development. New Engl. J. Med., 282: 933 (1970)

5. Cravioto. J.: Application of newer knowledge of nutrition in physical and mental growth and development. Amer. J. Pub. Health, 53: 1803 (1963):

6. Davidson, H.: The effect of famine in Germany on the children of Berlin with special regard to this city's orphans. Z. Kinderhlkd., 21: 349 (1919)

7. Downs, E. F. Nutritional dwarfing. Amer. J. Clin. Nutr., 15: 275 (1964)

8. Droese, W., and Rominger, E.: The effect of malnutrition on body weight and height in the childen of Schleswig-Holstein after the war. Z. Kinderhlkd., 67: 615 (1949).

9. Ernährungsbericht: Nutrition Report (Frankfurt, 1969)

10. Freund, J.: The present growth rate in newborn and small children. $Z$. Kinderhlkd., 67: 592 (1950)

11. Gesundheitsbehorde Hamburg, 2000 Hamburg 13, Tesdorpfstr. 8, West Germany.

12. Graham, G. G.: Effect of infantile malnutrition on growth. Fed. Proc., 26: 138 (1967).

13. Gramm, H.: The infant mortality since war end in Leipzig. Arztl. Wschr., 3: $535(1948)$.

14. Hultkranz, J. V.: About the increase in body heights in Sweden during the years of 1840-1926. Nova Acta Reg. Soc. Sci. Uppsal. (Vol. Extraord.,
Uppsala, 1927).

15. Institute for military medical statistics and documentation. 548 Remagen, Bergstrasse 38 (Letter of January 24, 1972).

16. Kraut, H.: The nutritional need of a physically working person. Arztl. Wschr. 3: 499 (1948)

17. Kellerer, H.: Statistics in Modern Economy and Sociality. (Rowohit, Hamburg, 1960).

18. Kendall, M. G.: Rank Correlation Methods (Griffin, London, 1970).

19. Lenz, W.: Peculiarities in infant growth. Homo, 8: 207 (1957).

20. Lenz, W.: Growth and physical development. In: H. Opitz and F. Schmid: Handbook of Children's Diseases. Kinderhlkd. Bd. Vol. 1, (Springer, New York, 1971)

21. Mayer, J. B.: The influence of hunger in a child. Monatsschr. Kinderhlkd., 97: $110(1949)$.

22. Ofenheimer, M.: A Kendall test against a U-shaped trend. Biometr. Z., 13: 416 (1971).

23. Prader A Tanner, J M and yon Harnack, G. A. Catch-up growth following illness or starvation. J. Pediat., 62: 646 (1963).

24. Schultze, M. O.: Effects of malnutrition in early life on subsequent growth and reproduction of rats. J. Nutr., 56:429(1960).

25. Sicgel, S., and Tukey, J. U.: A nonparametric sum of ranks procedure for relative spread in impaired samples. J. Amer. Stat. Ass., 55: 429 (1960).

26. Stutte, H.: Growth conditions in school children of Hessen in the years 194649. Kinderarztl. Prax. 19: 515 (1951)

27. Theopold, W., Hovels, O., Hartmann, W., and Uhland, R.: The development of body height in the second half of the 18th Century. Deut. Arztebl., 69: 611 (1972).

28. Vogt, D.: Clinical nutrition theory. II. Nutrition and child development. Wiss. Veroffentl, Deut. Ges. Ern., 15: 61 (1966).

29. von Kiil, X X. Stature and growth of Norwegian men during the past two hundred years. Skr. Utgitt Norske Vidensk.-Acad. Oslo Mat.-Naturvi- 
densk. Kl., No. 6 (1939).

30. We are most grateful to Dr. K. -H. Hölzer, I. Medizinische Universitätsklinik, Hamburg-Eppendorf, Germany, for cooperation and helpful discussions at every stage of the work. The data of the stature of 19-year-old men have been made available by the Institut für Wehrnedizinalstatistik und Berichtwesen, 548 Remagen, Bergstr. 38 (15). We wish to thank Dr. Bestet

Copyright (1) 1977 International Pediatric Research Foundation, Inc. meyer for his assistance in all questions concerning the material.

31. Requests for reprints should be addressed to: N. Dahlmann, M.D., Institut für Physiologische Chemie, der Universität Hamburg, Molekularbiologie Hamburg (Germany).

32. Received for publication August 21,1974

33. Accepted for publication September 3, 1975.

Printed in U.S.A.

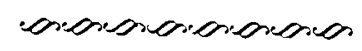

Announcement

Honorary and Emeritus Members of The American Pediatric Society

That portion of the Society membership rolls listing the Honorary and Emeritus members was inadvertently omitted from the Annual Mecting Program/Abstract issue, Volume 11, No. 4, April 1977 . It will be published in the June issue.

We sincerely regret this omission. The American Pediatric Society 